\title{
EL 666 DESDE UNA \\ PERSPECTIVA BÍBLICA
}

\author{
ERIK JiMÉNEZ MiLla \\ DOCENTE DE LA FACULTAD DE TEOLOGIA - UPEU
}

\section{Introducción}

Todo surge de la declaración de Juan: "Aquí hay sabiduría. El que tiene entendimiento, cuente el número de la bestia, pues es número de hombre, y su número es 666".

Históricamente uno de los primeros en creer que este asunto tenía que ver con el valor numérico de las letras de un nombre, los cuales sumarían 666, fue Ireneo (130-202 d.C.), identificando a la bestia como el anticristo. Pero al mismo tiempo previno que "es por lo tanto más seguro y menos peligroso esperar el cumplimiento de la profecía, que hacer conjeturas y buscar aquí y allí nombres que puedan presentarse, pues pueden presentarse muchos nombres que poseen el número mencionado". ${ }^{1}$

Tal como lo dijo Ireneo, este asunto se convirtió en una suerte de especulaciones y propuestas de nombres, que en su momento pudieron ser correctos, pero que determinan la sabiduría bíblica. ${ }^{2}$ Por esa

${ }^{1}$ Ireneo, Contra las herejías, 30.3.

${ }^{2}$ De las respuestas al significado del 666 se puede entender "el número de la bestia", varios son más viables que otros (la combinación de Beale, The Book of Revelation, 720-27; y Aune, Revelation, 771-3): (1) los nombres de varios líderes mundiales (el Papa, Hitler, Mussolini), por ejemplo, Sib. Or. 5.1-51 alude a los emperadores Alexander y Adriano por medio de la gematría, y las iniciales de los emperadores romanos de Julio César a Vespasiano (omitiendo Otón y Vitelio) es igual a 666; un símbolo del Anticristo o poderes anti-cristianos, en la que 666 es un número final para la humanidad en la rebelión contra Dios, que simboliza lo no completo (siete significa la perfección o la integridad en el libro) y sin, (5) un número triangular, específicamente la suma de los números 1-36 (=666), en sí mismo el 36 es un número triangular de los números 1-8 (= a la bestia como el rey de sesiones, 17:11) (así Lohmeyer, Farrer, Bauckham, The Climax of the Prophecy, 393-94). Ireneo (Contra las Herejías 5,30) menciona tres posibilidades, celebrada en la iglesia primitiva: "Euanthas" (desconocido), "Teitan" (los titanes de la mitología o quizás Tito, que destruyó Jerusalén en el año 70 DC y más tarde se convirtió en emperador), y “Lateinos” (el Imperio Romano). RBECNT, 519. 
razón, existe la posibilidad de abordar el tema desde otra perspectiva.

De los numerosos nombres latinos, griegos y hebreos para "666" -la mayoría de los cuales eran aplicados al papado- fue Lateinos el más frecuentemente preferido; mientras que Vicarius Filii Dei fue introducido por el profesor alemán Andreas Helwig. ${ }^{3}$

Es interesante resaltar la expresión "es número de hombre". Siendo que Apocalipsis no trata de identificar individuos, ya que los símbolos mayormente señalan poderes o reinos, la sabiduría de la cual se habla es necesaria. No se pretende ahondar en este tema, pero sí aplicar el significado del número tres en la Biblia, y la aplicación de éste en las profecías bíblicas.

Se intenta responder a las preguntas ¿qué significa realmente la expresión "seiscientos sesenta y seis”? ¿Es sabiduría aplicar el valor de las letras de un nombre cualquiera y buscar que la suma de éstos resulte "seiscientos sesenta y seis”? ¿De qué habla en sí la sabiduría, es sólo el entendimiento histórico de la profecía? ¿Cuándo se aplicará este número a la bestia?

En este artículo se plantea las siguientes hipótesis. La primera es que la expresión seiscientos sesenta y seis es simbólica. En segundo lugar, la sabiduría de la cual habla el verso no tiene nada que ver con

\footnotetext{
3“"Esta interpretación está basada en la identificación del papa como el anticristo, concepto que se expuso claramente en la Reforma. El principal expositor de esta interpretación fue Andreas Helwig (c. 1572-1643; ver L. E. Froom, The Prophetic Faith of Our Fathers, 2: 605-8). Desde los días de Helwig muchos han adoptado esta interpretación. Como este comentario identifica a la bestia como el papado, también acepta este punto de vista como el mejor que se ha presentado hasta ahora, aunque reconoce que en el criptograma puede implicarse más de lo que contiene esta interpretación". Ibid., 7: 337-38. La revista católica Our Sunday Visitor, del 18 de abril de 1915, informó en respuesta a la pregunta: “¿Cuáles son las letras que se supone que están en la corona del papa, y qué significan, si es que tienen significado?" Respuesta: "Las letras grabadas en la mitra del papa son éstas: Vicarius Filii Dei, que en latín significan Vicario del Hijo de Dios. Los católicos sostienen que la iglesia, que es una sociedad visible, debe tener una cabeza visible" (p. 3). La edición de la misma revista del 15 de noviembre de 1914, admitía que los números latinos sumados daban un total de 666 , pero añadía que muchos otros nombres también dan ese total. En el número del 3 de agosto de 1941, p. 7, nuevamente se trató el tema Vicarius Filii Dei, y se afirmó que ese título no está escrito en la tiara del papa. La tiara, se afirmaba, no lleva inscripción alguna (p.7). La Catholic Encyclopedia distingue entre mitra y tiara. Describe la tiara como un ornamento que no es litúrgico, y la mitra, como uno que se usa para ceremonias litúrgicas. Si la inscripción Vicarius Filii Dei aparece en la tiara o en la mitra, no tiene verdadera importancia. Se admite que el título se aplica al papa, y eso es suficiente para los propósitos de la profecía". $C B A, 7: 124$.
} 
identidad de nombres latinos y la equivalencia de sus letras. En tercer lugar, es una de las señales de un poder que según el mismo capítulo 13 persiguió a la iglesia por 1260 años y que al final del tiempo saldrá a la luz, y sólo se lo podrá aplicar el "conteo del número", cuando su herida sea completamente sanada y recupere el "poder, trono y gran autoridad", y esto está en un futuro próximo.

En primera instancia, se hace un repaso en la Biblia para encontrar el significado del número seis en la Biblia, después se hace lo mismo con el número tres, para finalmente extraer las lecciones teológicas de este ensayo. La metodología a usar es la bíblica-teológica.

\section{El significado del número "seis"}

En primer lugar, los especialistas en significado de números creen que el número "seis" es número de hombre. ${ }^{4}$ Representa al hombre y su naturaleza, siendo que éste fue creado el sexto día. Aunque este asunto no determine en primera instancia la situación pecaminosa, debido a la desobediencia pasaría a ser símbolo de la naturaleza pecaminosa. Piñero entiende que el seis significa la impotencia para alcanzar la plenitud. ${ }^{5} \mathrm{El}$ significado está dado entonces a la naturaleza humana y las consecuencias de una vida de apariencias y pecado.

Apocalipsis 22:15 refiere seis cosas interesantes relacionadas con el hombre, dice: "Afuera están los perros, los hechiceros, los inmorales, los asesinos, los idólatras y todo el que ama y practica la mentira". Como se percibe son seis los símbolos de pecado señalados. Así toma lógica la declaración de Proverbios 6:16: "Seis cosas hay que odia el Señor..". El número seis por lo tanto va ligado a la naturaleza del hombre y a su condición como consecuencia del pecado.

Dios estableció seis ciudades de refugio, que servirían de protección ante la venganza de sangre inocente (Jos 20). Goliat se destaca como enemigo de Dios, su altura era de seis codos y cuya punta de lanza pesaba seiscientos siclos de hierro (1 S 17:4-7). Nabucodonosor se desrology, 122-3.

${ }^{4}$ Para Hartill y Gunner, el número "seis", es número de hombre. Ver Davis, Biblical Nume-

${ }^{5}$ Piñero, Guía para entender el Nuevo Testamento, 505. 
tacó por su intención de tener la adoración divina, quien construyó una imagen de oro que medía sesenta codos de altura por seis de ancho.

Son seis los mandamientos que están ligados a la relación entre los seres humanos (Ex 20: 12). Por otro lado, fueron seis horas que estuvo Jesús suspendido en la cruz y paga la culpa de la humanidad caída (Mr 15:25, 33).

Esto indica que la expresión categórica que dice Apocalipsis 13:18 "es número de hombre", es una verdad que se desarrolla en la Biblia. Pero surge la interrogante ¿por qué Apocalipsis pone al seis repetido tres veces? En la siguiente sección se verá una explicación a esta inquietud.

\section{"Tres": símbolo de la Divinidad}

El primer tema es la creación, en donde aparece el número tres de manera indirecta, esto es a través del llamado quiasmo de la creación en el libro de Génesis, donde podemos observar dos grupos de tres que se relacionan entre sí. Obsérvese el siguiente cuadro:

Diagrama 1: Comparación del quiasmo de la creación (base $=3$ días por lado).

\begin{tabular}{|c|c|c|c|}
\hline $\begin{array}{l}\text { ler } \\
\text { día }\end{array}$ & Los cielos y la tierra & 4to día & El sol, la luna y las estrellas \\
\hline \multirow{2}{*}{$\begin{array}{r}\text { 2do } \\
\text { día }\end{array}$} & Las aguas y & \multirow{2}{*}{ 5to día } & $\begin{array}{c}\text { Los peces y los monstruos mari- } \\
\text { nos en las aguas }\end{array}$ \\
\hline & La expansión & & $\begin{array}{c}\text { Las aves para que vuelen en la } \\
\text { abierta expansión }\end{array}$ \\
\hline \multirow{2}{*}{$\begin{array}{l}\text { 3er } \\
\text { día }\end{array}$} & La tierra & \multirow{2}{*}{ 6to día } & $\begin{array}{c}\text { Los animales, el hombre para que } \\
\text { habiten sobre la tierra }\end{array}$ \\
\hline & las plantas & & $\begin{array}{l}\text { y se alimenten de toda planta que } \\
\text { Dios designó para comer }\end{array}$ \\
\hline
\end{tabular}

También es pertinente entender que son tres los atributos que abarcan todo lo que Él hace: la omnisciencia, la omnipotencia y la omnipresencia. ${ }^{6}$

${ }^{6}$ Johnston, Los números en la Biblia, 51. 
Otro punto a considerar, después de la creación, es el arca de Noé, que según Génesis 6:16 estaba compuesta de tres pisos “...y pondrás la puerta del arca en su costado; la harás con piso bajo, segundo y tercero". ¿Pero qué representaba el arca de Noé? Si se lo mira como el medio de salvación que Dios usó para el mundo antediluviano ya que fuera de ella no había salvación, se puede comprender que era un tipo de Jesús, el Salvador y único medio de salvación. ${ }^{7}$

Después de que el arca cumplió su labor salvífica, Dios hace un pacto con Noé, y recibe una triple bendición, que en realidad es casi la misma que recibieron Adán y Eva: "Y bendijo Dios a Noé y a sus hijos, y les dijo: Sed fecundos y multiplicaos, y llenad la tierra” (Gn 9: 1). También en el pacto con Abram se encuentran algunos detalles. En Génesis 15 , Dios se le presenta y le repite la promesa, pero antes de hacer el pacto le pide tres animales distintos de tres años (Gn 15). Los animales que se le indicó a Abram que usara eran precisamente los que más tarde prescribió Moisés como bestias para los sacrificios (Ex 29:15; Nm 15:27; 19: 2; Dt 21: 3; Lv 1:14). Es bastante interesante que cada vez que Dios establecía un pacto con el hombre lo selle, representando el énfasis o acción divina con la presencia del "tres", siendo ésta una manifestación trinitaria, ya que los tres actúan en forma conjunta.

Un detalle más en el libro de Génesis es la aparición de tres varones celestiales a Abraham para confirmar el pacto (Gn 18). Algunos expositores han pensado que los tres "varones" fueron las tres personas de la Deidad. Esto parece injustificable puesto que se alude a dos como a ángeles (Gn 19:1, 15; Heb 13:2) y como a hombres (Gn 19:10, 12, 16). ${ }^{8}$ Por lo tanto, lo más adecuado sería ver en los tres "varones" al Señor y a dos ángeles. Abraham reconoce que es Dios, y lo comienza a tratar como su Señor. Lo interesante es el mensaje de tres seres celestiales, esto se extenderá como aplicación al mensaje de los tres ángeles de Apocalipsis 14.

Otro evento relacionado es el de los tres días de oscuridad en la novena plaga de Egipto. Elena G. de White dice que cuando la lobreguez de las densas tinieblas se extendía como paño mortuorio sobre toda la tierra ¡Jehová de los ejércitos ordenó a la naturaleza que le proclamase Dios

${ }^{7} C B A, 1: 272$.

${ }^{8}$ Ibid., 1:339. 
verdadero; el Dios de Israel confirmó su supremacía y ejerció su poder para envilecer los ídolos, destruir la idolatría y librar a los descendientes de Abrahán de la tierra de su esclavitud. ${ }^{9}$

Habiéndose revelado así el Todopoderoso como el Dios verdadero, gracias a su intervención milagrosa, después de continuar ejerciendo su poder en las medidas adaptadas a destruir las distintas formas de idolatría que existían en Egipto, el undécimo y último milagro fue un castigo encaminado a manifestar a todos los intelectos que Jehová era el Dios que ejecuta juicios en la tierra. ${ }^{10}$

Es curioso ver cómo esta acción de tres días tenía relación con la adoración a Dios. Se entiende que Dios siempre le da un significado a lo que hace. Después de ello, el cordero pascual quedaría establecido y una de las tres fiestas anuales sería marcada. La sangre del cordero pascual, el cual representa a Cristo, quedaría señalada para siempre. Es interesante que tanto la tercera, la sexta y la novena plaga no fueron advertidas, llegaron sin anuncio, probablemente porque eran símbolo del poder de Dios, y que no dependían del diálogo de Moisés con el Faraón. ${ }^{11}$

Más adelante, Dios establece tres fiestas de convocatoria a todos los hijos de Dios. En Éxodo 23:14-16 y en Levítico 23, dicen que estas fiestas anuales eran: la Pascua, Pentecostés y la fiesta de las cabañas, en las cuales todos los hombres de Israel debían presentarse delante del Señor en Jerusalén. ${ }^{12}$

También el santuario está lleno de símbolos. Los mismos tres 1975), 824-5.

${ }^{9}$ White, Patriarcas y profetas (Buenos Aires: Asociación Casa Editora Sudamericana,

${ }^{10}$ Ibid., 825 .

${ }^{11} C B A, 1: 555-6$. "A semejanza de las plagas anteriores, ésta asestó un fuerte golpe a los dioses egipcios. Ra, el dios-sol, había sido el dios principal de Egipto durante siglos y cada rey se llamaba a sí mismo el "hijo de Ra". En el tiempo de Moisés, este dios era identificado con Amón y llevaba el nombre de Amón-Ra. Los más grandes templos que el mundo jamás haya visto fueron edificados en su honor y uno de ellos, el gran templo de Karnak en el Alto Egipto, todavía es magnífico aun estando en ruinas. Otro dios era el disco del sol, Atón, que unas pocas décadas después del éxodo llegó a ser brevemente el dios supremo del sistema religioso egipcio. Mediante la novena plaga fue claramente demostrada la completa impotencia de estos dioses para sus adoradores”. Ibid., 1:556.

${ }^{12}$ White, Patriarcas y profetas, 578. 
ambientes en donde descansaban los diferentes muebles del santuario siguen ilustrando la intervención de Dios. Y en el lugar más importante, el lugar santísimo, el arca del pacto contenía: las tablas de la ley de Dios, la vara de Aarón que floreció y el maná. Es interesante notar que en ninguna de ellas intervino el hombre. Estas tres son manifestaciones directas de Dios.

Los tres valientes de David, también esconden un significado especial con relación a Dios. Esta expresión se refiere a tres grandes hombres que actuaron en nombre de Dios (2 S 23:8). David realizó un censo, Dios le propuso tres cosas a realizar por su grave pecado. El profeta Gad le trajo a David ese triple mensaje registrado en 1 Crónicas 21: 12.

Posteriormente, vemos cómo el templo hecho por Salomón llega a ser construido en tres niveles, tres pisos en los cuales se establecerían los diferentes servicios, esto viene siguiendo el modelo del santuario que tenía tres ambientes para los muebles que se usaban (1 R 6: 6). Ezequiel 42: 3 también indica tres pisos o niveles en las cámaras del templo. ${ }^{13}$ Esto ilustra la intervención directa de Dios en este edificio.

Más adelante hay una expresión que escucha Isaías a los Serafines: "Y el uno al otro daba voces, diciendo: Santo, Santo, Santo, es el Señor de los ejércitos, llena está toda la tierra de su gloria" (Is 6:1). Otro mensaje de Dios dice: "A ruina, a ruina, a ruina lo reduciré tampoco esto sucederá hasta que venga aquel a quien pertenece el derecho, y a quien yo se lo daré". (Ez 21:27). Esto manifiesta que cuando se la reconoce o habla la Deidad, hay una repetición triple de las frases.

Daniel permite ver algunas representaciones. El profeta manifestaba su creencia en Dios, y a pesar del decreto del rey Darío "continuó arrodillándose tres veces al día, orando y dando gracias delante de su Dios (Dn 6:10)". Los tres jóvenes valientes de Dios que no se arrodillaron frente al acto blasfemo de Nabucodonosor (Dn 3), es un ejemplo de la adoración sólo al verdadero Dios. Un detalle quizás insignificante es el hecho de que el cuerno pequeño halla derribado a tres de los diez cuernos (Dn 7:8). Estos tres reyes eran los santos que no tuvieron miedo de enfrentar la muerte (Dn 7: 20).

${ }^{13}$ Warren Baker, The Complete Word Study Dictionary: Old Testament (Chattanooga, TN: AMG Publishers, 2003), 1150. 
Jonás estuvo dentro del pez tres días y tres noches, en donde sólo el poder de Dios lo sustentó. Dios intervino y su accionar le dio la oportunidad de vivir.

En el Nuevo Testamento sigue este énfasis relacionado con Dios, sobre todo en la intervención de la segunda persona de la Divinidad, Jesucristo. Las discusiones se han dado con el afán de aceptar la divinidad de Jesús. Pero al ver cómo es aplicado el énfasis del número tres en su vida, se da la idea correcta: Jesús es Dios.

El primero en mencionarlo es Mateo, clasificando la genealogía de Jesús en tres grupos de catorce generaciones (Mt 1:17). Seguidamente se descubre el nombre mismo de Jesús en su análisis contiene un número con tres números que tienen una relación con el número motivo de este estudio, $\mathrm{I} \eta \sigma$ o $v \varsigma(\mathrm{I}=10 ; \eta=8 ; \sigma=200 ; \mathrm{o}=70 ; v=400 ; \varsigma=200)$, equivale a 888, un interesante contraste con el número de la bestia, 666 . Quizás se ilustre mejor así:

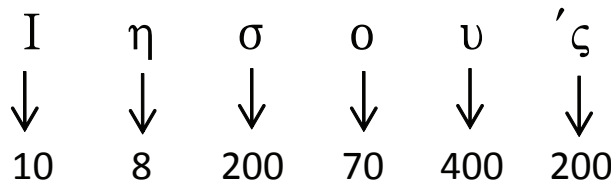

Inmediatamente la Biblia muestra las tres tentaciones de Satanás a Jesús (Mt 4:1-11), las cuales no fueron necesariamente para su naturaleza humana sino para su Divinidad. La orden "di que estas piedras se conviertan en pan" (v. 3) involucraba la creación de materia viva. El pan es vida. Las otras dos fueron contestadas categóricamente por Jesús, "No tentarás al Señor tu Dios" (v. 7) y ¡Vete, Satanás! Porque escrito está: “Al Señor tu Dios adorarás, y sólo a él servirás"(v. 10). Esta experiencia deja una clara evidencia de los motivos del conflicto cósmico: Satanás reclama el ser un dios, sin anular al verdadero Dios.

Otro aspecto relacionado son las tres veces que recibió la satisfacción del Padre hacia su labor. La primera fue en el Jordán en el momento del bautismo (Mt 3:17), la segunda en el día de la transfiguración, en presencia de tres de sus discípulos, (Lc 9:35) y la tercera vez, en el final ya de su vida delante de una multitud (Jn 12:28). Estas tres menciones de Dios de ninguna manera son casuales. 
La autoproclamación de Jesús "el Hijo del hombre es Señor del sábado" es mencionado en tres textos bíblicos (Mt 12:8; Mr 2:28 y Lc 6:5). Jesús, al ser Dios en la tierra, demostró su supremacía frente a la muerte, resucitando a tres personas en su ministerio: la hija de Jairo (Mt 9:23-27), el hijo de una viuda en el pueblo de Naim (Lc 7:12) y Lázaro (Jn 11).

Por otro lado, Jesús mismo relacionó su experiencia con la de Jonás y dijo: "porque como estuvo Jonás en el vientre del monstruo marino tres días y tres noches, así estará el Hijo del Hombre tres días y tres noches en el corazón de la tierra" (Mt 12:40). Se entiende por ello, desde el momento en que se lo elige para el sacrificio, esto ocurre en el Getsemaní. Desde ese momento, "jueves" de noche (sexto día para la Biblia) Jesús fue separado para el sacrificio y estuvo cumpliendo estrictamente su plan de acción. Este dependía de tres días y tres noches (Jn 20:1620). ${ }^{14}$ Por ello Elena de White escribe: "Tan agudamente pesó sobre É1 la pecaminosidad del pecado que por un momento la copa tembló en su mano y todo el cielo oyó el grito agonizante: "Padre mío, si es posible, pase de mí esta copa" (Mt 26:39). El Dios Omnipotente sufrió con su Hijo". ${ }^{15}$

${ }^{14}$ Desde el jueves por la noche, Jesús ya no contaba con la comunión que compartía con su Padre, ya que los pecados del mundo cayeron sobre él, quien es el verdadero Cordero. Ahora Jesús estaba solo, enfrentando al mismo enemigo. Y completó esta tarea el primer día de la semana al presentarse a su Padre. Si contamos los días son: viernes (6to día, tarde y mañana), sábado (7mo día, tarde y mañana) y domingo (1er día, tarde y mañana).

${ }^{15}$ White, Alza tus ojos, 221. "Podemos apreciar apenas débilmente la angustia inenarrable que sintió el amado Hijo de Dios en Getsemaní, al comprender que se había separado de Dios al llevar el pecado del hombre. Él fue hecho pecado por la especie caída. La sensación de que se apartaba de él el amor de su Padre, arrancó de su alma angustiada estas dolorosas palabras: "Mi alma está muy triste hasta la muerte". "Si es posible, pase de mí este vaso". Luego, con completa sumisión a la voluntad de su Padre, añadió: "Empero, no como yo quiero, sino como tú". El divino Hijo de Dios desmayaba y se moría. El Padre envió a un mensajero de su presencia para que fortaleciera al divino Doliente, y le ayudara a pisar la senda ensangrentada. Si los mortales hubiesen podido ver el pesar y asombro de la hueste angélica al contemplar en silencio cómo el Padre separaba sus rayos de luz, su amor y gloria, del amado Hijo de su seno, comprenderían mejor cuán ofensivo es el pecado a la vista de Dios. La espada de la justicia iba a ser desenvainada contra su amado Hijo. Por un beso fue éste entregado en manos de sus enemigos y llevado apresuradamente al tribunal terreno, donde había de ser ridiculizado y condenado a muerte por mortales pecaminosos. Allí, el glorioso Hijo de Dios fue "herido por nuestras rebeliones, molido por nuestros pecados" (Is 53:5.) Soportó insultos, burlas e ignominiosos abusos, hasta que "fue desfigurado de los hombres su parecer, y su hermosura más que la de los hijos de los hombres" (Is 52:14), White, Joyas de los testimonios, 1:223-4. 
En la hora de su muerte, Cristo Jesús establecería varias enseñanzas relacionadas con el énfasis tres o símbolo de Dios. Pedro negó a Jesús tres veces, rechazó a Dios y su poder para ayudarlo, prefirió confiar más en sí mismo que en Dios. ${ }^{16}$ El énfasis de tres se lo encuentra en los mismos detalles de la cruz. En primer lugar, la hora de la crucifixión relaciona a Jesús con Dios, la tercera hora (Mr 15:25). Otro detalle se encuentra en las tres cruces que se levantaron en el día de la muerte de Cristo (Mt 27:38; Mr 15:27; Lc 23:33; Jn 19:18), indudablemente el que estaba en esa cruz era Dios, quien teniendo el poder para librarse no lo haría.

Pilato también escribió un letrero y lo puso sobre la cruz. Y estaba escrito: Jesús Nazareno, El Rey de los Judíos, pero lo peculiar es "que lo puso en tres idiomas" (Jn19:13). Con este acto, sin darse cuenta Pilatos reconocía a Jesús como Dios.

La expresión "al tercer día resucitará", fue dada tres veces por Jesús anunciando su muerte (Mt 16:21; 17:23; 20:19). Y lógicamente se cumplió cuando Jesús resucitó al tercer día (Mt 28). Esta frase no es nueva en la Biblia. En diferentes momentos de la historia bíblica aparecen estas expresiones en donde se denota la presencia y el retorno de una oportunidad que da Dios hacia el ser humano. Un ejemplo de esta representación: "al tercer día”, como accionar de Dios, es la experiencia del pacto de Dios con el pueblo de Israel (Éx 19:11-16).

Siguiendo este mismo énfasis, la historia de Ezequías describe lo siguiente: “... al tercer día subirás a la casa del Señor” (2 R 20:5). También ocurrió en la historia de Ester. "Y aconteció al tercer día que Ester se vistió con sus vestiduras reales y se puso en el atrio interior del palacio del rey delante de los aposentos del rey" (Est 5:1). Cristo también se aparecería al tercer día. También se puede ver en Oseas, cuando describe la respuesta del pueblo: "Nos dará vida después de dos días, al tercer día nos levantará y viviremos delante de Él' (Os 6:2). Todos estos eventos describen la intervención de Dios, es por ello que el énfasis "tres" cobra importancia en toda circunstancia bíblica y representa a una constante participación divina.

Al continuar observando la vida de Cristo, se ve que en el cometido, la Gran Comisión, dada en Mateo 28:19-20, se encuentra el secreto divino o los pasos correctos para la realización de la obra del Señor.

${ }^{16}$ White, Cada día con Dios, 260. 
Estos tres pasos están ligados uno con otro, y no pueden existir independientemente. Discipular, bautizar y enseñar, son los pasos correctos y bíblicos para la labor misional de la iglesia. Si se hace esto, Dios mismo promete estar con nosotros, porque no es una obra humana sino divina. Pero cuando se incumple uno de ellos, por ejemplo el primero, y no se hace la labor de discipulado, pretendiendo bautizar a las personas sin prepararlas, se comete pecado, porque no se hace la voluntad de Dios.

En la experiencia de Pedro, cuando a eso de la hora sexta, estaba orando a Dios y le sobrevino una visión. En esta visión observó un lienzo gigante que descendía del cielo con todos los cuadrúpedos de la tierra, y la orden de Dios "Pedro levántate, mata y come". Aparentemente, Pedro reconoció la voz de su Maestro, pero aunque la orden se le repitió tres veces, ahora le tocó a Pedro negarse tres veces a obedecerla, por lo que el lienzo fue subido nuevamente. En ese instante, tres personas estaban en la puerta para llevar a Pedro a predicar a los gentiles. Una orden de Dios hace que él comprenda que ahora el evangelio de salvación no sólo era para los judíos sino para todos los gentiles. Es claro lo que se percibe, puesto que Dios mismo guió este proceso.

Pero la "gran comisión" de ir por todo el mundo (Mt 28:19-20) es ratificada en Apocalipsis 14:6-12 en el Mensaje de los tres ángeles, que en realidad es un solo mensajero, pero es presentando como un triple mensaje divino, tomando el símbolo de accionar de Dios en el significado del tres, y como es algo de origen divino, es una tarea que no puede errar. Al tener "tres" en su estructura, viene a ser como un mensaje de Dios, por lo que será acompañado de toda la plenitud de su poder. Sin embargo, parece contradictorio a lo que se viene explicando, porque el número tres representa a Dios y su accionar también puede, según algunos pasajes, representar a las acciones de un ser vivo (sea hombre o ángel) que pretende dicha atribución divina. Lo que se podría llamar un "atrevimiento blasfemo".

Un ejemplo es la plenitud de la apostasía del hombre que se resume en tres cosas según Judas 11: “¡Ay de ellos! Porque han seguido el camino de Caín, y por lucro se lanzaron al error de Balaam, y perecieron en la rebelión de Coré". Se quiere dar a entender la blasfemia en tres individuos representativos de este mal.

En Apocalipsis aparece la manifestación de la trinidad satánica. Para entenderlo mejor, se lo estudiará en la siguiente sección. 


\section{EI "tres" y Apocalipsis}

Al ser Apocalipsis el punto principal de este estudio, es necesario encontrar una relación de las cosas que contengan este símbolo bíblico para referirse a Dios y a su accionar. Sin lugar a dudas que el "tres" está presente en este libro.

Apocalipsis prácticamente comienza con una secuencia de tres expresiones y éstas no son el resultado de la casualidad. Se ratifica, representan a Dios expresando su autoridad. Para descubrir esta idea, Apocalipsis 1 , introduce una secuencia de tres, que vienen desde el versículo 1, en donde está la autoridad de la revelación, Jesús, ángel y Juan. El versículo 2 describe lo que el ángel describirá o revelará, él dice: “el cual dio testimonio de la palabra de Dios, y del testimonio de Jesucristo, y de todo lo que vio". El versículo 3 describe en qué consiste recibir la bendición de Dios: el que lea, el que oye y el que guarda.

Inmediatamente el versículo 4 determina tres características de lo que es Jesús, a él se lo llama, "el que es, el que era, el que ha de venir". Estas características se repiten en forma de símbolo tres veces en Apocalipsis $(1: 4,8 ; 4: 8)$. Ya varios autores han mencionado, que esta relación de frases, ilustran la autoridad de Dios en este mundo y en el universo. La Biblia nos da la interpretación de estas expresiones, la cual llega a una comprensión mejor cuando se lee las tres veces que aparecen en Apocalipsis 1.

Diagrama 2: Las tres características de Jesús en Apocalipsis 1

JESÚS

ILUSTRACIÓN DE APOCALIPSIS CAP. 1

\begin{tabular}{|l|l|l|}
\hline Ap 1:4 & Ap 1:8 & Ap 1:18 \\
\hline Es & Es & Vivo \\
\hline Era & Era & estuve muerto \\
\hline \multirow{2}{*}{$\begin{array}{l}\text { ha de venir } \\
\text { el Todopoderoso }\end{array}$} & \multirow{2}{*}{ ha de venir } & vivo por los siglos y tengo las \\
\cline { 3 - 3 } & & llaves de la muerte \\
\cline { 3 - 3 } & & y el hades \\
\hline
\end{tabular}


Ya se escribió acerca de la similitud de estas características con las que se le atribuyen a la Bestia de Apocalipsis $17 .{ }^{17}$ Estas características "era", "ya no es" y "será", revelan su blasfémica intención, de imitar a Dios y gobernar en su nombre sagrado, utilizando las credenciales que sólo le corresponden a Jesús.

Apocalipsis en sí mismo, está estructurado en base al número tres. Esto se ve en la repetición constante de ciclos de tres: tres ciclos históricos: los sellos, las trompetas y las copas $(4: 1-8,1 ; 8: 7-12 ; 15: 5)$; tres ayes (8:13); tres batallas escatológicas $(12: 7 ; 19: 11 ; 20: 7)$; la trinidad satánica (Dragón, bestia y falso profeta) que emiten tres espíritus inmundos a manera de ranas (16:13). Tres veces queda asombrado Juan con las visiones que recibió $(5: 4 ; 7: 13$, en el 17:7).

LaRondelle encuentra tres características que cumplen las promesas de Cristo a los fieles en Apocalipsis 2 y 3: los tronos, los vestidos blancos y las coronas de victoria $(3: 5,11,21)$ ". ${ }^{18}$

Pero Apocalipsis acaba con una descripción positiva de un Jesús viniendo por tercera vez, para reinar en este mundo y lo hace descendiendo con una ciudad. La descripción de esta ciudad es interesante ya que en sus tres dimensiones tiene la misma medida en longitud, en anchura y en altura, y también tan igual que en la época del santuario, en donde las tribus iban distribuidas tres a cada lado. Esta ciudad tiene tres puertas en cada lado del cuadrado de la ciudad. Todo esto es descrito en el capítulo 21:16: "Y la ciudad está asentada en forma de cuadro, y su longitud es igual que su anchura. Y midió la ciudad con la vara, doce mil estadios; y su longitud, anchura y altura son iguales". Sin duda, se distingue como la ciudad de Dios, y basta esta expresión para entender que será algo realmente imponente, ya que es el mismo Dios el Constructor.

Como se ve, en la historia bíblica hay suficientes elementos para entender que el uso del "tres" tiene mucho que ver con el actuar de Dios.

Davis presenta una tabla denominada "The Interpretations of Symbolic Numbers", en donde presenta las conclusiones de Terry, Lange y

${ }^{17}$ Para un mayor estudio, ver Erik Jiménez Milla, "La bestia de Apocalipsis 17 y la aparición de Satanás en la tierra”, Estr 6, 1 (2009): 18-20; Ibid. “¿Cuatro o siete imperios universales?”, Estr 6, 2 (2009): 37-48.

${ }^{18}$ LaRondelle, Las profecias del fin, 116-7. 
Gunner en cuanto a la representación del "tres" en la Biblia. El primero, Terry cree que el "tres" representa a la Plenitud Divina en unidad, y es el número de Dios. El segundo, Lange dice que representa la vida, el espíritu, la resurrección de la vida nueva, espíritus inmundos, etc. Y por último, Gunner ratifica el significado del número tres diciendo que representa a la trinidad de personas en la Deidad y a los actos poderosos de Dios. ${ }^{19}$

Se menciona este asunto tan complejo, porque llega a ser una de las cosas que la bestia hace para tomar el control de la humanidad. Esta estrategia aunque parece nueva, es milenaria. Apocalipsis 13 establece que la acción final de la bestia, no sufrirá ninguna modificación, será la misma y se resume en el engaño dado a Eva. Si bien es cierto y correcto que el cuerno pequeño es el principal denunciado, es necesario comprender que se trata más que todo de una filosofía bien trabajada por el enemigo de Dios, y que es el cuerno pequeño el principal expositor de este mensaje. Mientras nos acercamos al final de la historia este pensamiento tendrá que proliferar.

\section{"Seiscientos sesenta y seis" y su única aparición en el AT}

La única mención específica de este número en otra parte de la Biblia fuera de Apocalipsis, es en el Antiguo Testamento en 1 Reyes 10:14, al decir: "El peso del oro que Salomón tenía de renta cada año, era seiscientos sesenta y seis talentos de oro". En esta descripción, que según el Comentario Bíblico Adventista representaba las riquezas y la gloria de Salomón, aparecen muchas indicaciones de "debilidad moral". La excesiva acumulación de plata y oro y la multiplicación de caballos eran una violación de las amonestaciones dadas por Moisés (Dt 17:16, 17). ${ }^{20}$

La poligamia trajo abajo a Salomón y le hizo perder su reino, pero lo que preparó el camino para su corrupción total y su idolatría posterior fue la acumulación de riquezas. Por esta razón Moisés menciona la poligamia en el mismo contexto de la acumulación de caballos y plata y oro (Dt 17:16, 17).

La pregunta que surge en el contexto de este artículo es ¿cuál es la relación con el seiscientos sesenta y seis de Apocalipsis? La respuesta es

${ }^{19}$ Davis, Biblical Numerology, 123-4.

${ }^{20} \mathrm{CBA}, 2: 783$. 
simple. La aparente acumulación de riquezas, la fama y la gloria señalan la tragedia humana. Todo este desorden, pretensión y orgullo, aunque con un aparente respeto a Dios, tiene un triste final que se resume en la poligamia y la idolatría.

Salomón es una muestra de ello, al establecer vínculos matrimoniales con mujeres paganas llegó a alejarse de la voluntad de Dios y las consecuencias llegaron a ser evidentes (Ex 34:11-16; Dt 7:1-4). Salomón, que debiera haber dado el mejor ejemplo de obediencia a esta orden y que tendría que haber hecho respetar la ley, se convirtió en su más descarado infractor. Un hombre que había sido el más sabio de todos, llegó a ser también el más necio. Nunca hay sabiduría al ir en contra de una orden explícita del Señor.

El cuerno pequeño ostenta mucha riqueza, en lugar de mostrar la humildad con la que el mismo Jesús mostró al venir en la tierra, ha creado una imagen de gloria, pompa y poder. Desde su mismo origen, ha sido algo que ha tenido como bandera la grandeza de sus templos, los adornos y artes exagerados, mostrando su afán de aparecerse a las religiones paganas, terminando igual a ellas estableciendo la idolatría y otras costumbres que no las aprueba ni aprobará Dios.

\section{Significado del "seiscientos sesenta y seis"}

El enemigo ha tratado de desviar la atención de este número al terror, sin embargo, nada de lo que la Biblia quiere simbolizar debe entenderse desde esta perspectiva.

La sabiduría a la que aquí se hace mención es la divina, tal como Pablo lo declara cuando afirma que las cosas de Dios “.... se han de discernir espiritualmente" (1 Co 2:14). La aplicación del "tres", es por la triple repetición del seis. Considerando que el seis representa al hombre, aplicando el "tres" se entiende que ejemplifica a un hombre que se cree Dios. Éste es el cuerno pequeño.

Entonces, la interpretación más real y bíblica, es que dado el énfasis triple de un número, no tiene nada que ver con el significado de un número sucesivo, en donde el número anterior, el 665 podría tener un significado, y el número posterior también; sino que tiene que ver con un símbolo de pretensiones divinas. Es así que este número ejemplifica 
al ser humano que pretende atributos divinos. Lógicamente, éste cree en Dios, habla de él, pretende mostrase como celoso de la voluntad divina, pero todo es una farsa, porque ha caído en el engaño milenario de Satanás, "seréis como Dios" (Gn 3:5). Este texto es determinante, presenta a un Dios que aparentemente es respetado, pero en la práctica es el hombre que pretende ser "un dios" que puede gobernarse sin la dirección de Él. Este significado se ve reflejado en forma perfecta en la declaración referida al cuerno pequeño: "el hombre de pecado, el hijo de perdición, el cual se opone y se exalta sobre todo lo que se llama dios o es objeto de culto, de manera que se sienta en el templo de Dios, presentándose como si fuera Dios (2 Ts 2:3-4).

La palabra "sabiduría" tiene que ver con la aplicación del símbolo hacia la vida diaria, donde cada creencia es llevada a la práctica. Entonces, no es sabiduría sólo el reconocer en la historia al poder que persiguió por más de mil años y que cambió los tiempos y la ley, y analizar su desarrollo a través del tiempo. Inclusive, no consiste sólo en distinguir su accionar actual. Entonces, llegado el momento final, "sabiduría" es darse cuenta que sólo se honra a Dios al hacer su voluntad.

Así la interpretación toma un giro especial, no sólo nos lleva a una interpretación futura, sino al presente, cuando al intentar creer en Dios cada quien a su manera y tener una religión que se adapte a las prácticas $\mathrm{y}$ vidas pecaminosas de la modernidad, el hombre se acerca a ser marcado por la Bestia. Se debe recordar a Salomón, el hombre que había sido el más sabio de todos, llegó a ser también el más necio. Nunca hay sabiduría al ir en contra de una orden explícita del Señor. El final de la desobediencia es la idolatría.

La tendencia actual va encaminada por el "seiscientos sesenta y seis", quien pretende ser muy religioso, muy celoso, muy reverente, muy santo, pero su corazón está lejos de cumplir con lo que la Biblia enseña. Una situación parecida se tendrá que vivir al final de los días, los hombres creerán que están haciendo la voluntad de Dios, pero habrán sido engañados por este poder humano que cree poder hablar en nombre de Dios.

La serpiente no intentó hacer que Eva dejara de creer en Dios, era evidente que no podía hacerlo porque ella lo había visto, sino que la estrategia que usó para su rebeldía sería la misma que él cree poder lograr 
para él y los ángeles que lo siguen. ${ }^{21}$ Toda la historia muestra que ese siempre ha sido el problema del diablo (Is 14: 12-14) y del ser humano.

Entonces, el énfasis del número tres en el 666 identifica las intenciones del ser humano de imitar el acto blasfemo de la Bestia. Manejar la vida bajo el propio pensar, creyendo que Dios aprueba, es estar preparándose para ser parte del engaño final de la Bestia. Esta aplicación puede entenderse de la siguiente manera: cada vez que el hombre toma una decisión, sin importarle lo que Dios piensa de ello, aunque diga respetar y amar a Dios, es un candidato a recibir el engaño del 666 y cuando en nombre de Cristo intentar establecer el "reino falso de Cristo" en la tierra. Por esta razón, decir: "Yo creo en Dios a mi manera", es peligroso.

Al final de los tiempos no habrá ateos, todos tendrán que creer en Dios, porque es la plataforma para que el 666 entre en acción. Al cuerno pequeño sólo podrá aplicársele este número cuando recupere las tres dimensiones que tenía antes de caer, "poder, trono y grande autoridad" (Ap 13:2), descrito en el mismo capítulo de Apocalipsis en que aparece el 666. Sólo allí se podrá ser testigo de las grandes "fornicaciones", e idolatría que se establecerá. Al tener la riqueza y el poder, se cree tener la "autoridad" para hacer en nombre de Dios todo lo que quiera, pero Dios hace rato que ya lo desechó.

Por ello, todas las iglesias cristianas que adapten las creencias bíblicas a sus propias filosofías humanas y no a un "escrito está", corren el peligro de prepararse para caer y unirse al poder que desde sus inicios ha blasfemado y adulterado de esa manera. La creación, el sábado, la segunda venida de Cristo, el milenio y muchas otras más, ya han sido modificadas por este poder. Cuando el Cuerno Pequeño vuelva a asumir el control del mundo tratará de que los verdaderos hijos también acepten estos cambios, que no son más que pruebas de una "poligamia" ya profetizada.

Satanás quiso ser como Dios. Pero él no puede negar la existencia de Dios, porque ha visto cosas que el hombre hoy no lo logra imaginar en su realidad. También sabe que no puede anular a Dios de la mente de sus

\footnotetext{
${ }^{21}$ Isaías 14:12-14. Satanás no dijo que destruiría a Dios, ni que lo destronaría. Él sabía que no podía, porque conoce a Dios y ha visto el poder que tiene. Por eso este texto dice: "Junto a las estrellas de Dios, levantaré mi trono", "sobre las alturas de las nubes subiré y seré semejante al altísimo".
} 
criaturas, entonces ha creado una filosofía extraña, demoníaca, que se la puede intentar narrar: "Sigue creyendo en Dios, habla de él, lo menciona en todo, habla de la Biblia, pero tú también eres Dios, por lo que algunas decisiones son tuyas ya que tienes libertad, y esto gracias a que tiene esencia divina". Ése es el problema, cada vez que un ser humano decide hacer su propia voluntad, desechando la voluntad divina, se coloca en el terreno de este engaño, y hay un número que al final de la historia marcará su accionar, porque terminará unido a la bestia y su engaño final.

Todos los humanos en algún momento de sus vidas han caído en este error, pretendiendo ser dioses al querer hacer su propia voluntad y no la de Dios. Pero, así como la sentencia que Dios le dio a Salomón tenía una esperanza, "por amor a mi hijo David conservaré una tribu para salvación"; así también por amor a Jesús, Dios tiene un pueblo que será rescatado de este engaño, los cuales desecharán al "seiscientos sesenta y seis" y aceptarán a Jesús como su Dios, el único que tiene el verdadero "poder, trono y autoridad". 